on Australia's outstanding record in medical research. He rightly praises Barry Marshall and Robin Warren for their work on Helicobacter pylori, which won the 2005 Nobel Prize in Physiology or Medicine. But Macfarlane Burnet, Peter Doherty and Suzanne Cory are barely mentioned, and Jack Eccles, Frank Fenner, Don Metcalf, Gus Nossal and Jacques Miller are ignored.

The most thoughtful element in Barlow's book is a brief examination of the comparative value of individual versus collaborative research; he should have expanded this argument. He expresses concern that Commonwealth and state funding of research may involve too much fanfare about multidisciplinarity at the expense of research by individuals. Darwin's research and Einstein's celebrated 1905 papers would have been too small to qualify for Australian Research Council (ARC) grants, and I suspect that Burnet, a notorious loner, might have looked in vain for funding from the National Health and Medical Research Council.

The proof-reading is careless. We are treated to a quotation from Arthur Koestler twice. And Barlow dismisses Australia as a "relatively small economy", even though The Economist ranks Australia as number 15 in the world. The book also suffers from the lack of an index.

Barlow is right to point out the Australian public's high level of interest in science, but is dismissive, even contemptuous, about complaining academics. He fails to examine the reasons for this paradox. He should have commented on the striking fall in enrolments in the enabling sciences, physics, chemistry and mathematics, parallel to the relentless march of the business students. Research disciplines are down proportionally (but not in absolute numbers) while the packaging and marketing subjects are well up. Was this worth a sentence or two?

Barlow is unduly modest and says little of his time advising Nelson. He mentions the case of Trofim Lysenko, the Soviet geneticist who suppressed darwinism, and asserts that nothing similar could happen in Australia. I am not so sure. Australia practises its own form of soft lysenkoism, with climate scientists in CSIRO silenced if they do not produce 'agreed science', supporting the Howard government's ideological rejection of global warming. 'Public good' Cooperative Research Centres were closed down unless they worked on commercial products. The ARC's recommendations were subject to ministerial veto, and a chair and chief executive appointed for expertise in research were replaced by people experienced in working with government and interpreting, or even second-guessing, shifts in policy.

Barry Jones is a vice-chancellor's fellow at

Melbourne University. He was Australia's science minister from 1983 to 1990. His autobiography, A Thinking Reed, will be published in October.

\title{
Renaissance man
}

Thus Spoke Galileo: The Great Scientist's

Ideas and their Relevance to the Present Day

by Andrea Frova \& Mariapiera Marenzana

transl. by Jim McManus

Oxford University Press: 2006. 512 pp.

$\$ 34.50, \ldots 19.99$

\section{Giorgio Parisi}

Galileo Galilei is known as one of the founders of modern science. But his works, as well as those of co-founders such as Isaac Newton, are seldom read. It is not that they are in some exotic language: Newton wrote in Latin, Galileo mainly in a limpid, straightforward Italian, in contrast to the baroque style of many of his contemporaries. As well as science, Galileo is a major figure in Italian history and literature. Italian high schools teach his dramatic life and prosecution by the Inquisition. But professional historians of science aside, few Italians have read many of his works.

The problem is that we must understand the scientific questions, knowledge and - most importantly - prejudices of the time. Changes in scientific notation make the scientific papers of even a century ago all but unintelligible to today's experts, so it is no surprise that scientists are seldom moved to read 400-year-old books of physics whose scientific context almost completely escapes them.

Thus Spoke Galileo by Andrea Frova and Mariapiera Marenzana, an attempt to bring Galileo's work to general readers, should solve this problem. The texts are introduced in their correct and precise historical context, framed to stimulate the reader's curiosity.

The book opens with an imaginary autobiography, composed of a collage of letters and other documents written by Galileo, interpolated with writings from Frova and Marenzana in Galileo's style. Galileo tells his life story, discussing the clash with the Church that eventually led him to disown his writing. It is a portrait of a complex man, with light and shade. He was frank, but also able to adapt himself to difficult times: he knew that his forced abjuration was only a momentary defeat, and that in the long run, with the help of his students, his ideas would triumph.

Each of the other chapters deals with a specific topic. They begin with a summary of the knowledge at that time, followed by Galileo's writings on the subject. The most crucial points are put in his words; the rest of the argument is summarized. Often the chapter ends with a short historical excursus where, presenting the same ideas in modern scientific language, the authors show the impact of Galileo's ideas on subsequent science.

To understand the originality and ingenuity of a scientist we must compare his statements with those of his contemporaries. It turns out that Galileo leant on the work of other scientists more than is commonly believed: the famous example of the ship in motion is taken from Giordano Bruno, and an argument on the fall of a heavy body comes from Giovanni Battista Benedetti. Galileo's unique skill was to

\section{Galileo in the gallery}

Galileo's influence on science and culture is celebrated in art and on stage in Britain this summer.

Bertolt Brecht's play The Life of Galileo examines the conflict between reason and faith, a theme with current resonance. This month sees the revival of a version of this play by David Hare at the National Theatre in London. Directed by Howard Davies and starring Simon Russell Beale, it runs until the end of October.

Galileo's book Sidereus Nuncius (The Starry

Messenger) lends its title to an exhibition at the Compton Verney gallery in rural Warwickshire. The Starry Messenger: Visions of the Universe explores how science and technology have changed the way we think about the Universe, and the role of artists in transmitting these ideas. Early scientific texts are on display alongside paintings, music and video installations by artists ranging from William Blake to Fred Tomaselli (shown here). The exhibition runs until 10 September.

www.nationaltheatre.org.uk

www.comptonverney.org.uk

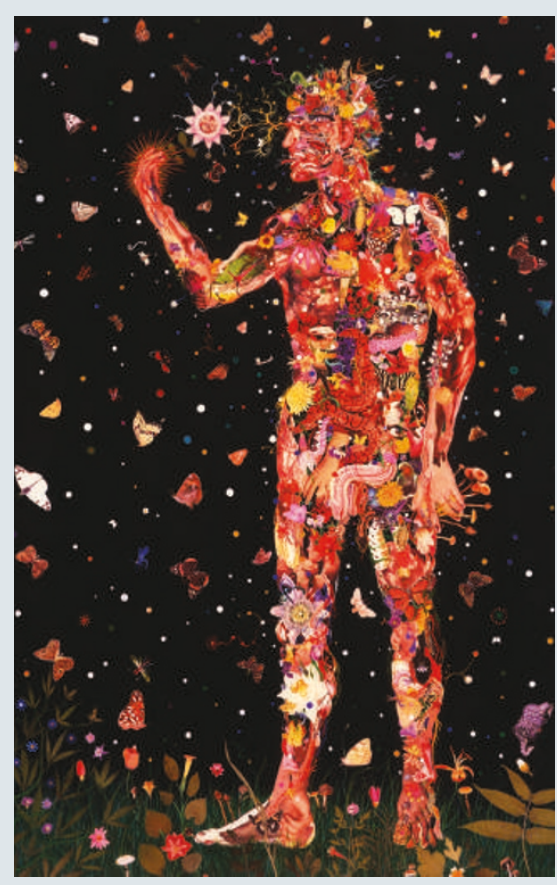

